\title{
Peritoneal and Retroperitoneal Neoplasm
}

National Cancer Institute

\section{Source}

National Cancer Institute. Peritoneal and Retroperitoneal Neoplasm. NCI Thesaurus. Code C7337.

A benign or malignant, primary or metastatic neoplasm that affects the peritoneum and/or retroperitoneum. 